This manuscript 'Photonic seismology in Monterey Bay: Dark fiber DAS illuminates offshore faults and coastal ocean dynamics' is a non-peer reviewed preprint, which has been submitted to Science for peer review. We encourage your feedback.

\author{
Nate Lindsey (natelindsey@berkeley.edu) \\ UC Berkeley/ Lawrence Berkeley National Laboratory \\ Craig Dawe (dacr@mbari.org) \\ Monterey Bay Aquarium Research Institute \\ Jonathan Ajo-Franklin (JBAjo-Franklin@lbl.gov), \\ Lawrence Berkeley National Laboratory
}




\title{
Photonic seismology in Monterey Bay: Dark fiber DAS illuminates offshore faults and coastal ocean dynamics
}

\author{
Nathaniel J. Lindsey, ${ }^{1,2, *}$ T. Craig Dawe, ${ }^{3}$ Jonathan B. Ajo-Franklin ${ }^{2}$, \\ ${ }^{1}$ University of California, Berkeley, Earth \& Planetary Science Department, \\ 300 McCone Hall, Berkeley, CA, 94720, USA \\ ${ }^{2}$ Lawrence Berkeley National Laboratory, Berkeley, Energy Sciences Division, \\ 1 Cyclotron Road, Berkeley, CA, 94720, USA \\ ${ }^{3}$ Monterey Bay Aquatic Research Institute, \\ 7700 Sandholdt Road, Moss Landing, CA, 95039, USA
}

*To whom correspondence should be addressed; E-mail: natelindsey@berkeley.edu.

Emerging fiber-optic sensing technology coupled to existing subsea telecommunications cables can provide access to unprecedented seafloor observations of both ocean and solid earth phenomena. During March 2018, we conducted a Distributed Acoustic Sensing (DAS) measurement campaign along a buried fiber-optic cable typically used for data transfer to and from a scientific cabled observatory offshore Monterey Bay called the Monterey Accelerated Research System (MARS) node. During a 4-day period of MARS node maintenance the MARS cable was repurposed as an evenly-spaced $\sim 10,000$-component 20kilometer-long DAS array. Full wavefield observation of a M3.4 earthquake that occurred 45-km inland near Gilroy, CA illuminated multiple recentlymapped and previously unmapped submarine fault zones, which were observed to slow the propagating wavefront and act as point scatterers reradiat- 
ing body-wave energy as Scholte waves. In the shallow water of the MARS cable $(h<100 \mathrm{~m})$, dominant noise $(\mathbf{f} \sim 0.1-0.3 \mathrm{~Hz})$ was found to match the predicted seafloor pressure field induced by shoaling ocean surface waves, otherwise known as the primary ocean microseism. DAS amplitudes track sea state dynamics during a storm cycle in the Northern Pacific, correlating with features of local bay buoy and onshore broadband seismometer data streams. We also observed secondary microseisms $(\mathbf{f} \sim 0.5-2 \mathrm{~Hz})$. Decomposing the incoming and outgoing wavefield components of the primary microseism noise we validated the Lougnet-Higgins-Hasselmann theory that bi-directional ocean wind-waves setup by the coast reflection undergo nonlinear wave mixing to cause the secondary microseisms, even when the outgoing energy is only $1 \%$ of the incoming energy. We observe additional noise patterns at higher and lower frequencies that are consistent with previous point sensor observations of post-low-tide tidal bores $(f \sim 1-5 \mathrm{~Hz})$, storm-induced sediment transport $(f \sim 0.8-10 \mathrm{~Hz})$, infragravity waves $(f=0.01-0.05 \mathrm{~Hz})$, and breaking internal waves $(f \sim 0.001 \mathrm{~Hz})$. The number of geophysical interactions observed over this brief four-day dark fiber recording evidences the introduction of an important new technique for seafloor science.

Introduction Geophysical observations mostly occur on land because technical, logistical and financial challenges hinder sensor array deployments on the ocean floor. Offshore observation gaps have produced critical knowledge gaps and even bias in research areas like marine ecology (1), ocean circulation (2), coastal erosion (3), offshore seismic hazards (4,5), submarine volcanology (6), and deep earth structure (7).

This is most obvious in physical oceanography, where hydrodynamics are constrained by 
single point observations. These experiments often alias complex short spatial wavelength oceanographic processes. To address this challenge, new distributed autonomous sensor networks have been deployed. The ARGO floats (8) and Ocean Observing Initiative (9) are presently recording pressure, water velocity, salinity, and/or temperature offshore with subgrid, multi-year resolution. These data have already created new insights into cross-shelf and nearshore transport (10), ocean mixing, and even eruption observations of difficult to monitor submarine volcanoes (11).

In the field of marine geophysics, experiments are conducted using one of three methodologies: 1) multi-month ocean bottom seismometer campaigns; 2) a small number of tethered observatories (MARS, (12); ALOHA, (13); NEPTUNE, (14), AXIAL (15), S-net (16)); or 3) large marine research vessel cruises that aim to develop seismic reflection images, map bathymetry, and collect samples from the seafloor. Each tool has its limitations (i.e., power, memory, permitting, telemetry, trawling damage, sub-optimal data retrieval rates, operations and maintenance requirements), which amount to major financial costs and often prohibit discovery. Up-scaling any strategy to observe multi-scale physics, and map or monitor hazardous plate boundaries worldwide is difficult to envision.

New seafloor sensing modalities are critical to seismic and tsunamic hazards. In northern California, for example, large Holocene-active seismogenic faults near the Mendocino triple junction, Hosgri and San Gregorio faults, as well as parts of the San Andreas fault are all primarily offshore $(17,18)$.

Resolution of earth's interior properties are also dependent on the global seismometer distribution. The recent call for Scientific Monitoring and Reliable Telecommunications (SMART) cables in which sensors would be attached along the $1.5 \times 10^{9} \mathrm{~m}$ of subsea cables at optical repeater sites every $65 \mathrm{~km}(13)$ is estimated to backfill this observational gap by tripling raypath coverage across the Pacific, Indian and Atlantic oceans (7). 
Moreover, developing new seafloor seismology and ocean acoustics methodologies is necessary for shoreline-crossing research directions that aim to track typhoons and hurricanes in realtime, understand offshore fault properties in connection with slow-slip and subduction zone processes, capture the origins of Earth's ocean microseism noise, and engineer and monitor seafloor infrastructure, among many other applications.

Emerging fiber-optic sensing approaches connected to unused telecommunication fibers has demonstrated a high-impact to provide dense geophysical information onshore $(19,20)$, but there is an even greater opportunity offshore. marra2018 considered one iteration of this idea where transmission of ultra-stable laser pulses inside a transoceanic subsea cable is used to measure average cable strain.

A different style of photonic measurement, presented in this paper, involves phase-based coherent optical time-domain reflectometry ( $\phi$-OTDR) measurements, or Distributed Acoustic Sensing (DAS). DAS transforms tens of kilometers of a fiber-optic cable into a dense ( $\sim 1 \mathrm{~m}$ / sensor), Large-N (10,000's of sensing points), broadband ( $\sim 1 \mathrm{mHz}-10 \mathrm{kHz})$ strain-meter array using a stable laser and an optical interferometer connected to one end of a single-mode fiber-optic. Multiplexed dynamic strain measurements are made by rapidly probing the twoway propagation paths of photons injected into the fiber, which travel at known speed and undergo Rayleigh scattering at density fluctuations embedded by standard fiber-optic manufacturing practices. In the present DAS archetype, $\sim 40,000$ optical phase shift measurements are recorded every $0.005 \mathrm{~s}$ and are directly proportional to the strain-rate field resolved over $10 \mathrm{~m}$ segments of the fiber. Since 2015, DAS has been used across the oil and gas industry as an inexpensive replacement to traditional downhole seismic geophone arrays, often utilized for vertical seismic profiling (VSP). Most recently, DAS has been applied to study earth systems, including earthquakes (19-23), noise (24-26), and hydrogeology (20,27). In a marine setting, DAS has not been evaluated, but could enable relatively inexpensive, access to high quality acous- 
tic/elastic observations, complementing or in some cases altogether circumventing the need to manage a submersible sensing package in the harsh ocean environment.

In this paper, we present novel DAS observations using an existing offshore telecommunications fiber located in Monterey Bay, CA. We begin by studying how an earthquake's elastic wavefield interacts with offshore fault zones in the San Gregorio Fault System, and use DAS density to identify new faults. Second, we investigate the dominant background noise around $\mathrm{f} \sim 0.1 \mathrm{~Hz}$, and use array processing to validate and quantify the widely-accepted nonlinear Lounguet-Higgins-Hasselmann hypothesis that has been widely used to explain how shoaling coastal wind-waves produce a double-frequency effect in ocean microseism noise. Then, we track the evolution of microseism energy through a full Pacific storm cycle, relating DAS signals to sea state changes observed in operational forecasts, buoys, and onshore broadband seismometers. Mulitfarious nearshore hydrodynamics are also identified (e.g., tidal bores, infragravity waves, sediment transport on the seafloor, internal gravity waves), which span an exceptionally-broad frequency range $(0.001 \mathrm{~Hz}-10 \mathrm{~Hz})$ and thus demonstrate the oceanographic observation potential of DAS. Finally, using surface buoy data, we show that horizontal fibers embedded in seafloor muds sense axial strain in response to both oceanographic pressure fields and seismological solid earth wavefields. Seafloor DAS therefore enables a number of novel array-type observations at the intersection of oceanography and seismology.

Dark Fiber DAS recording with the MARS cable The Monterey Accelerated Research System (MARS), one of the first deep-sea scientific observatories, was developed over a decade ago to support seafloor instrumentation, including broadband ocean-bottom seismometer MOBB $(18,28)$. MARS is located on the continental slope outside Monterey Bay, California at a depth of $891 \mathrm{~m}$ (Fig. 1). It is powered and controlled from Moss Landing, CA using a 51-km-long subsea cable. The MARS cable contains a 10-kW copper conductor and eight single-mode (SM) 
optical fibers $(12,29)$. It was originally buried at a depth of up to $1 \mathrm{~m}$ below the northern shelf of Monterey Bay at an average water depth of $45 \mathrm{~m}$, and recently found to be undisturbed (30).

On March 9, 2018, the MARS cable and node were de-energized for annual maintenance, during which time a commercial DAS interrogator (Silixa iDAS, ver. 2) was connected to the shore terminus of one of the optical fibers (see Supplementary Materials for description of the LBNL-MBARI Offshore DAS Dark Fiber Experiment). Over the next four days, 3.2 TB of seismic data were recorded from 9,984 sensing points (DAS channels) spaced every $2 \mathrm{~m}$ over $20 \mathrm{~km}$ of cable length from Moss Landing to south of Santa Cruz.

Earthquake wavefield analysis Earthquakes insonify the crust. While only a fraction of this energy is captured by sparse seismic networks, DAS arrays have the potential to sample earthquake wavefields in an unaliased fashion. For example, a local minor earthquake with energy in the frequency range $\mathrm{f}<10-50 \mathrm{~Hz}$ traveling through the shallow crust has dominant wavelengths around $20-50 \mathrm{~m}$, which a 10-m gauge length DAS experiment can accurately sample without loss of information. This means seismic waves conventionally labeled as quasirandom coda because of the spatial aliasing effect of a survey with $100 \mathrm{~m}-100 \mathrm{~km}$ sensor separations, can now be tracked and analyzed as deterministic phases exhibiting coherent moveout over short length scales. Passive earthquake recording with high-resolution DAS should thus expose elastic wave propagation and scattering features, especially when dark fiber networks are used to capture wavefields over tens of linear kilometers. Adapting seismic imaging techniques to passive earthquake DAS recordings potentially offers additional insight into crustal structure where ever optical fiber exists $(19,22,23)$.

On 2018-Mar-11, a M3.4 vertical strike-slip earthquake occurred 44.7-km northeast of Moss Landing near Gilroy, CA at $2.83 \mathrm{~km}$ depth. DAS observations of the seismic wavefield recorded by the MARS cable are plotted in Fig. 2 . The records have a high central frequency ( $\sim 15 \mathrm{~Hz})$ 
due to the event size and proximity. Minimal data processing was applied (see Supplementary Materials). The resulting subsurface strain dataset resembled an unmigrated active-source seismic shot gather. P, pP, PP, S and SS arrivals matched predicted arrival times for the USGS cata$\log$ moment tensor solution and cable geometry. The P-wave was not visible on some traces and barely visible elsewhere, potentially due to the particle motion orientation relative to the fiber axis $\left(\theta>71^{\circ}\right)$. Converted $\mathrm{pP}$ and $\mathrm{PP}$ phases had greater horizontal components and were more robustly observed. The S-wave is poorly observed above the P-wave coda, especially when compared with the stronger SS phase, possibly due to cable azimuth, fiber coupling, and/or reduced amplitude over cable azimuth due to a node in S-wave radiation.

2-D time-domain beamforming of the Gilroy event $(\mathrm{f}=5-15 \mathrm{~Hz}$ ) found that energy arrived over a wide azimuth range from north to east. Equal components arrived from the catalogued epicenter backazimuth of $81^{\circ} \mathrm{N}$ and a direction around $45^{\circ} \mathrm{N}$ (Fig. 2e). We interpreted this as evidence of seismic multipathing through the complex 3-D North American - Pacific plate boundary (31). A second source of scattering was found to originate from local structure immediately below the seafloor cable. This type of scattering is discussed next.

Following the passage of each seismic phase, strong coherent seismic energy was observed to propagate linearly in both a forward and reverse direction at an apparent velocity of 200 - 600 $\mathrm{m} / \mathrm{s}$ from a discrete locus of origin points (Fig. 2b-d). Scattering was identified most clearly between 15.1 - $16.3 \mathrm{~km}$ and also between 8.4 - $10.3 \mathrm{~km}$ on the MARS cable, but similar features were observed at several additional locations with less fidelity. Some scattering locations are strong while others are weak or appear overprinted by stronger scattering. This unique spatial pattern of scattering was also observed in the wavefield generated by a subsequent M2.7 aftershock. We interpret these scattering features as the interaction of body waves with discrete sub-vertical seafloor fault discontinuities, which act as point scatterers. Measured wavespeed suggests conversion into Scholte waves propagating below the seafloor interface. The coher- 
ence length of the scattered waves was measured as $200-400 \mathrm{~m}$, robustly resolved by 100 - 200 independent fiber-optic sensing points (minimum resolution of $30 \mathrm{~m}$ after smoothing).

High-resolution seismic-reflection imaging recently conducted in our study area $(32,33)$ identified extensive paleocanyon deposits of variable thickness $(<200 \mathrm{~m}$ underlain by bedrock) buried below the continental shelf near Monterey and Soquel canyons, as well as four previously unmapped NW-SE striking faults with sub-vertical dip whose locations transect the MARS cable obliquely at an angle of $\sim 30-40^{\circ}$ around $15-17 \mathrm{~km}$ and again near $19 \mathrm{~km}$ (see Fig. 1). The mapped faults lie in what is now referred to as the Aptos Fault Zone, a major step-over relay between the San Andreas Fault Zone onshore and the San Gregorio Fault Zone offshore, and are included in the USGS Fault and Fold database. Mapped fault locations correlate with the observed secondary scattering locations from the Gilroy M3.4 event (faults marked by white arrows in Fig. 2b,d). Fig. 2c shows the wavefield observations for a section of Monterey Bay where faults were not previously identified. Because of the high feature similarity, we interpret this segment as a previously unidentified segment of the Aptos Fault Zone, which we thus observe extending an additional $15-20 \mathrm{~km}$ to the SSE parallel to the shoreline and potentially connecting to Monterey Canyon.

Wavefront tracking of the main SS phase (Fig. 2d) showed slowdown that was restricted to a $2 \mathrm{~km}$ zone from $14.5 \mathrm{~km}-16.5 \mathrm{~km}$ coincident with the interpreted fault zone around $15.1-16.3$ km (Fig. 2d). The delay was as large as $0.25-0.3$ seconds. Assuming the wavefront propagated in a vertical plane with the cable axis at this location, the observed arrivals were reduced from $2.1 \mathrm{~km} / \mathrm{s}$ to $1.2 \mathrm{~km} / \mathrm{s}$ over less than $1 \mathrm{~km}$. In a pioneering study of the San Andreas fault zone gouge, li1990 used an active-source borehole seismic array to observe this waveguide effect through two narrow fault gouge zones that were found to have wave speeds of $1.0-1.8 \mathrm{~km} / \mathrm{s}$. We interpret our observations in the context of this phenomenon, as the interaction of seismic waves with a highly-fractured, low velocity fault zone gouge layer. 
Characterizing offshore fault hazards near densely-populated coastal areas is exceptionally difficult and expensive, especially over long time periods (i.e. Large-T). The passive offshore imaging techniques demonstrated here with DAS could be utilized to find, characterize and even monitor fault zones, and their properties over decades. Note that a Large-N seismic experiment with a 100-m station spacing could resolve the bulk seismic wavefront perturbation, but would still alias the secondary scattering off of point scatterers.

Observations of ocean primary microseism Globally, seismometers record persistent vibration between 0.05 and $0.5 \mathrm{~Hz}$. Subaerial array experiments conducted since the 1960's have concluded that this noise largely comes from ocean-solid earth interactions and refer to it as the oceanic microseism noise band (34-37). This motion is predominantly composed of Rayleigh waves with distinct P-wave phases $(38,39)$. Although this topic is as old as observational seismology itself, many questions remain. How do ocean wind-gravity waves transfer energy to the continents? How is this ocean-soild earth energy budget amplified/modified by coastline geometry, shore slope, water depth, seafloor materials, and storm activity? Dark fiber DAS experiments have a unique opportunity to address these questions, which have broad scientific import to oceanography, ambient noise seismology, and coastal engineering.

A preliminary but critical question is what is the sensitivity of the DAS fiber technique? It is evident from the Gilroy earthquake analyzed above that the cable is at least partially in rigid contact with the solid earth. We hypothesize that oceanographic signals are also recorded. In the shallow water condition of the MARS cable (20 to $50 \mathrm{~m})$, we expect that the principal oceanographic strain signal is due to the pressure field generated by propagating surface gravity wind-waves, otherwise known as the primary ocean microseism. MARS cable DAS recordings were dominated by strong ocean microseism noise in the range $\mathrm{f}=0.05-1 \mathrm{~Hz}$. Bromirski and Duennebier, 2002 (36) describes that the hydrodynamic force of the primary microseism $\left(P_{b}\right)$ 
depends on surface wave amplitude and local bathymetry as:

$$
P_{b}=\frac{\rho g z}{\cosh (k h)}
$$

where $\mathrm{z}$ is wind wave height. To test this prediction, we analyzed DAS strain records from 1.5-20 km along the MARS cable every 10 minutes, using the wave height time history from the buoy to estimate $\mathrm{z}$ (Fig. $4 \mathrm{c}$ ). Fig. 5 shows that at $\mathrm{f}=0.056 \mathrm{~Hz}$, recorded DAS strain amplitudes are accurately explained by a primary microseism model. Although horizontally-oriented seafloor fibers have no azimuthal sensitivity to vertical hydrostatic load changes, such cables have been shown to undergo strain through the Poisson response of the fiber package (27), and also could record transverse seafloor current motions. Future work is needed to quantify this relationship on an absolute scale over a longer observational window, potentially using colocated DAS/hydrophone/buoy measurements, and also considering seafloor compliance effects (40).

Primary microseisms produced in shallow water by individual wave loads during shoaling $(36,38)$ should also obey the shallow water wave dispersion equation:

$$
\omega^{2}=g k \tanh (k h)
$$

where the dominant signal frequency $(\omega=2 \pi f)$ is related to both wavenumber $(k)$ and water depth $(h)$. A representative raw microseism noise observation from 2018-Mar-10 and 10 - 17 $\mathrm{km}$ along the MARS cable is plotted in Fig. 3 with its frequency-wavenumber domain (see Supplementary Materials). As predicted, the dominant DAS strain energy is a dispersive wave group with frequency content around $\mathrm{f}=0.05-0.15 \mathrm{~Hz}$. Under the assumption that all primary microseism energy in the range $0.05-0.15 \mathrm{~Hz}$ is caused by local wave height as discussed in the previous section, the outgoing components can only be due to coast reflection. We find that the reflected energy in this frequency band is approximately $1 \%$ of the incoming energy, hypothetically because most of the energy couples into the continent or is dissipated in the process. 
Direct observation of secondary microseisms generated near the coast The accepted theory for secondary microseism noise generation is attributed to (41), which was expanded to random fields by (42). The Longuet - Higgins - Hasselmann hypothesis predicts that opposing wind-wave trains mix nonlinearly and generate secondary microseisms with specific wave characteristics, such as near-acoustic wavespeeds. Scholte waves are the name given to Rayleightype wave motion propagating at the ocean and solid earth interface, and often associated with the secondary microseism wave mode. A number of authors routinely show indirect lines of evidence in support of the Longuet - Higgins - Hasselmann hypothesis, but direct observation of the energy transfer has only been documented in one deep ocean environment by muyzert2007, primarily because validation requires observing both opposing ocean waves and the resulting Scholte wave mode generation.

In situ secondary microseism generation was recorded by the DAS array as weak energy around $\mathrm{f}=0.25-1.5 \mathrm{~Hz}$ and $\mathrm{k}=+/-0.003 \mathrm{~m}^{-1}$, traveling much faster than the wind-waves $(\mathrm{c}=500-2000 \mathrm{~m} / \mathrm{s})$. This secondary microseism feature shows symmetric amplitude components propagating in both directions at an amplitude level that is $1.5-2 \mathrm{~dB}$ below the primary microseism amplitude level. In deeper water, the hydrodynamic signal of the primary microseism should attenuate below the level of the secondary microseism. This accords with the theory that nonlinear bi-directional wind-wave mixing near shore produces an acoustic wave at the sum of the incoming and outgoing frequencies and difference of the wavenumbers, even when outgoing waves are vanishingly small. Thus, the outgoing component's existence setup by the coast reflection serves as a kind of probe signal, pumping energy from the stronger incoming primary microseism into directionally-invariant Scholte waves.

Multi-instrument observations of sea state evolution Next, we investigated how the recorded microseisms evolved during the four-day experiment. The primary microseism amplitude is 
used here as a proxy for sea state $(43,44)$. The global wave prediction model WaveWatchIII (45) was used to determine the timing of storms in the North Pacific.

On 2018-Mar-09, the first storm propagated west-to-east across the North Pacific Ocean where it made land fall on the west coast of North America at the latitude of Oregon, before slowly diminishing in size. After a 24-hour quiescent period, a second storm sweeps into the area beginning on 2018-Mar-11 from Alaska. This storm breaks up on 2018-Mar-13, elevating significant wave height in Monterey Bay. Time series of local buoy wind speed, direction, and significant wave height (Fig. Fig. 4b,c) strongly correlated with this storm activity, with 3 - 9 hour phase lags consistent with the storm-bay separation.

To better characterize the primary microseism energy transfer process across the shoreline, we compared time-frequency spectrograms from the fiber located at the seafloor interface with the buoy at the water surface and an onshore seismometer (see Fig. 4; see Supplementary Materials for methods).

Storm activity correlated with elevated primary microseism noise in the range $0.05-0.2$ $\mathrm{Hz}$ on the DAS, buoy, and seismometer. While the broad pattern in this band is remarkably consistent over the primary microseism band, small absolute frequency shifts and amplitude discrepancies identified between the instrument records suggest important differences in sensor type (vertical displacement buoy; horizontal strain DAS; horizontal velocity seismometer), coupling and site effects, or complex ocean-solid earth coupling.

At higher frequencies, around $0.2-0.5 \mathrm{~Hz}$, the buoy and seismometer recorded a unique 18-hr activity pattern associated with the second storm on 2018-Mar-13. This energy does not appear on any DAS record from the MARS cable. Because these secondary waves are not recorded by the DAS, we hypothesize that this signal is gerneated in deep water off of the continental shelf, and that when it propagates through the nearshore environment the signal is many orders of magnitude weaker than the strong local primary microseism noise. We hypothesize 
that coupling and cable orientation could also mitigate this energy depending on the mode of wave propagation.

Broadband hydrodynamic signals Figure 6 documents broadband time-frequency exploration of the DAS dataset at one position around $5.5 \mathrm{~km}$ on the MARS cable over 5 decades of bandwidth. This analysis identified a number of additional hydrodynamic signals outside the microseism band that ranged from oscillations of one cycle every half hour ( $f \sim 0.0008-0.001$ $\mathrm{Hz}$ ) up to $5-10 \mathrm{~Hz}$.

At the beginning of the experiment, diffuse background noise was present above the microseism band $(\mathrm{f}=0.5-7 \mathrm{~Hz})$. Environmental seismic noise in this band has been observed near rivers, and theoretically linked to grain-grain collisions during river bedload transport (46-48). We interpreted this as sediment transported/entrained by seafloor currents in the footprint of the MARS cable. As the storm deteriorates, this noise lessens, possibly because seafloor current energy dissipates.

Twice during the quiet portion of the DAS experiment, transient strain signals were observed around 1 - $2 \mathrm{~Hz}$, lasting $\sim 1-2$ hours. These signals correlated with the initiation of rising tide. We hypothesize that this marks the arrival/dissipation of semi-diurnal internal tidal bores propagating across the northern shelf $(49,50)$. (51) documented tidal bores with 1-hour duration using vertical temperature and salinity sensing profiles at two different locations on the southern shelf of Monterey Bay. Tidal bores are mixing events associated with the tidally-forced migration of cold, low-density water. As such, the DAS signals may be due to thermal strain, or related to the local elastic displacement response of high amplitude solitons (52).

Below the microseism band $(\mathrm{f}=0.01-0.05 \mathrm{~Hz})$, we observed tidally-modulated long-wave infragravity signals. This signal was first interpreted using the submarine broadband seismometer BK.MOBB supported by the MARS cable (44). 
A strong peak was observed at approximately $0.001 \mathrm{~Hz}$ using the widest window $(7,200$ seconds). This feature had one or sometimes two higher harmonics, and was strongest on 2018-Mar-10 and attenuated over the experiment. A strong tidal modulation was observed, gliding between $\mathrm{f}=0.0008 \mathrm{~Hz}$ and $0.0015 \mathrm{~Hz}$ during high and low tide, respectively. Weak correlation was identified between this signal and the well-documented Monterey Bay seiche modes, specifically those at $\mathrm{f}=0.0009 \mathrm{~Hz}$ and $0.001 \mathrm{~Hz}(53,54)$. An alternative hypothesis is that these are solid earth vibrations generated by turbulent mixing of internal gravity waves breaking at steep-topography near the MARS cable, perhaps at the continental shelf break $(<15$ $\mathrm{km})$ or inside the Monterey Canyon $(<5 \mathrm{~km})$. Internal waves (IWs) are slow-moving vertical oscillations of ocean stratification interface, which separates the deep, cold, saline-rich ocean from the warmer, lighter surface waters (55). IWs enhance cross-shelf transport of fluid and biology, and are therefore foundational in models of thermohaline ocean ciruclation and marine ecology. Slow-moving IWs are routinely observed using satellite imagery, and have also been imaged in the water column using active-source marine reflection surveys (56-58), and recently found to produce small tilt signals on subaerial broadband seismometer records communication H. Shaddox, 2019 (?)). Regardless of which mechanism cased this signal, it is among the lowest frequency natural DAS observations to-date.

Future directions Pairing fiber-optic sensing technologies with subsea fiber-optic telecommunications infrastructure creates the opportunity to validate existing scientific hypotheses and motivate new ones. The current work, based on a brief experiment during the maintenance period of a scientific cabled observatory successfully located submarine faults that would be unknown without a marine seismic reflection cruise campaign and validated an accepted but unobserved mechanism for how ocean noise is created along coasts. We also documented a number of broadband oceanographic phenomena. Continuously recording these signals, effec- 
tively expanding the observation window from four days to the average $\sim 25$-year lifetime of an optical fiber, will advance our ability to probe the oceanographic-seismological sound system with novel observations of those the processes documented here response to tidal, seasonal, annual, and climatic variation and forcing (59).

Multi-decade fiber-optic sensing experiments could also capture the full spectrum of earthquake cycles at plate boundaries worldwide. Broadband DAS observations paired with a distributed static strain Brilluoin sensing measurement could effectively measure tectonic creep, interseismic slow-strain, and seismic rupture phases all in one platform, without the need to modify the cable and with only minimal shore instrumentation. Emerging photonic tools could also be co-opted as monitoring strategies for next-generation applications and research in offshore earthquake and tsunami early warning, marine ecology, marine mammal monitoring, coastal erosion, ocean acoustic tomography, and seafloor engineering.

Expectations of offshore wind development, deep-sea mining, seafloor data centers, and $5 \mathrm{G}$ broadband internet connectivity will continue to drive demand for submarine optical fiber networks, presenting a near-term opportunity for the geoscience community to leverage this expansion as a sensing resource to solve address basic and applied problems.

Acknowledgements N.L. was supported by the National Science Foundation Graduate Research Fellowship under Grant No. DGE 1106400. The experiment was made possible by the Laboratory Directed Research and Development(LDRD) Program of Lawrence Berkeley National Laboratory under U.S. Department of Energy Contract No. DE-AC02-05CH11231, which also supported J.A-F. Subsequent analysis has been supported by the GoMCarb project under the Assistant Secretary for Fossil Energy, Office of Coal and Power Systems through the National Energy Technology Laboratory, of the U.S. Department of Energy, under contract No. DE-AC02-05CH11231. The MARS observatory is funded under the NSF Award ID 1514756 
with additional support from the David and Lucille Packard Foundation/MBARI. Access to the MARS cable optical fiber was provided by the MBARI. We would like to thank Silixa for longterm partnership in support of our DAS acquisition efforts. The authors would like to thank D. Dreger, B. Romanowicz, S. Holbrook, L. Retailleau, L. Gualtieri, T. Mittal, and C. Paull for their collaborative and insightful comments. WaveWatch-III analysis was based on original script by S. Maurya. GMT was used to create the map. Obspy and Matplotlib were used for seismic data analysis and plotting. Data used to generate the figures and support the findings of this manuscript are available here: igithub repo link $_{i}$.

Author contributions Statement N.L. conceived of and designed the experiment, recorded and analyzed the data, and wrote the manuscript. C.D. enabled MARS cable access, and assisted in field operations. J.A-F. supported the project, contributed to the manuscript, and supervised the analysis. 
A

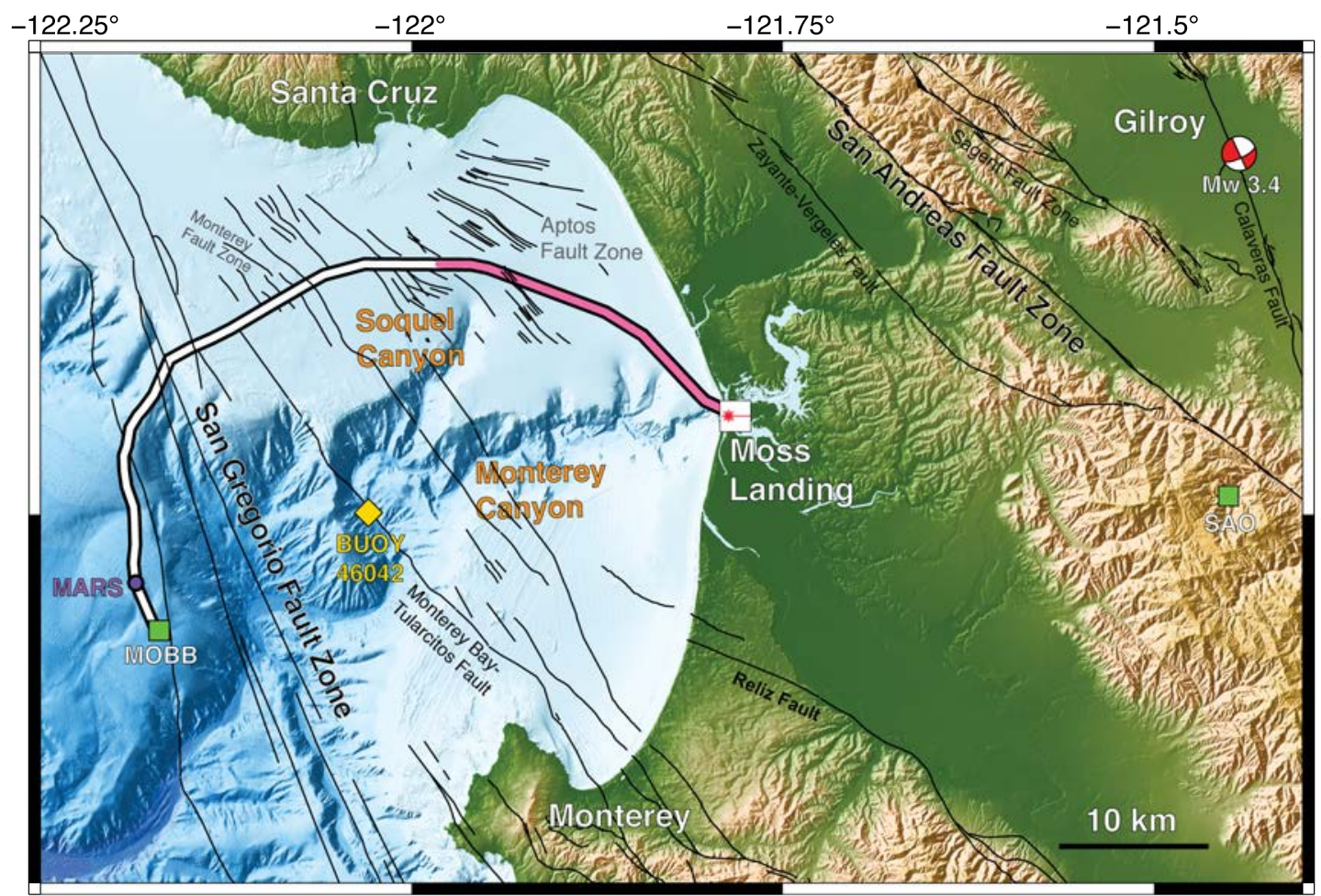

B

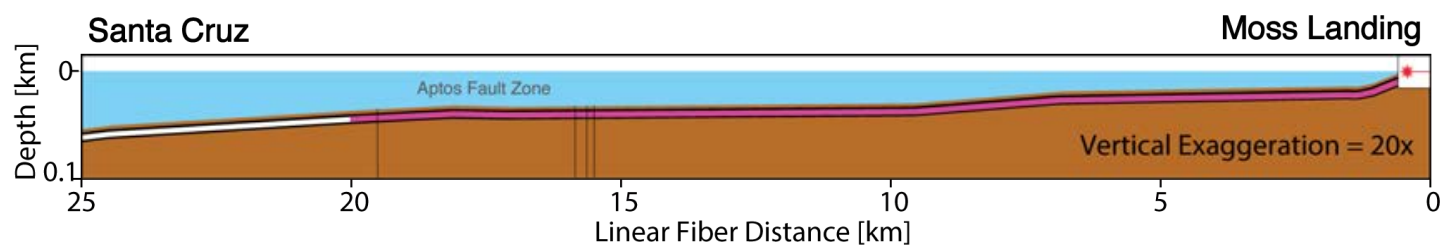

Figure 1: a.) Map of Monterey Bay, CA shows the 51-km MARS cable (pink portion used for DAS), mapped faults, M3.4 2018-Mar-11 Gilroy earthquake (star), auxiliary broadband seismometers (green squares), NOAA buoy 46042 (yellow diamond), and major bathymetric features. b.) Cartoon cross-section of illuminated MARS cable array illustrates that the MARS cable is buried $1-\mathrm{m}$ below the seafloor under $20-50 \mathrm{~m}$ of water. Note the mapped fault locations around 16 and $19 \mathrm{~km}$ linear fiber distance. 

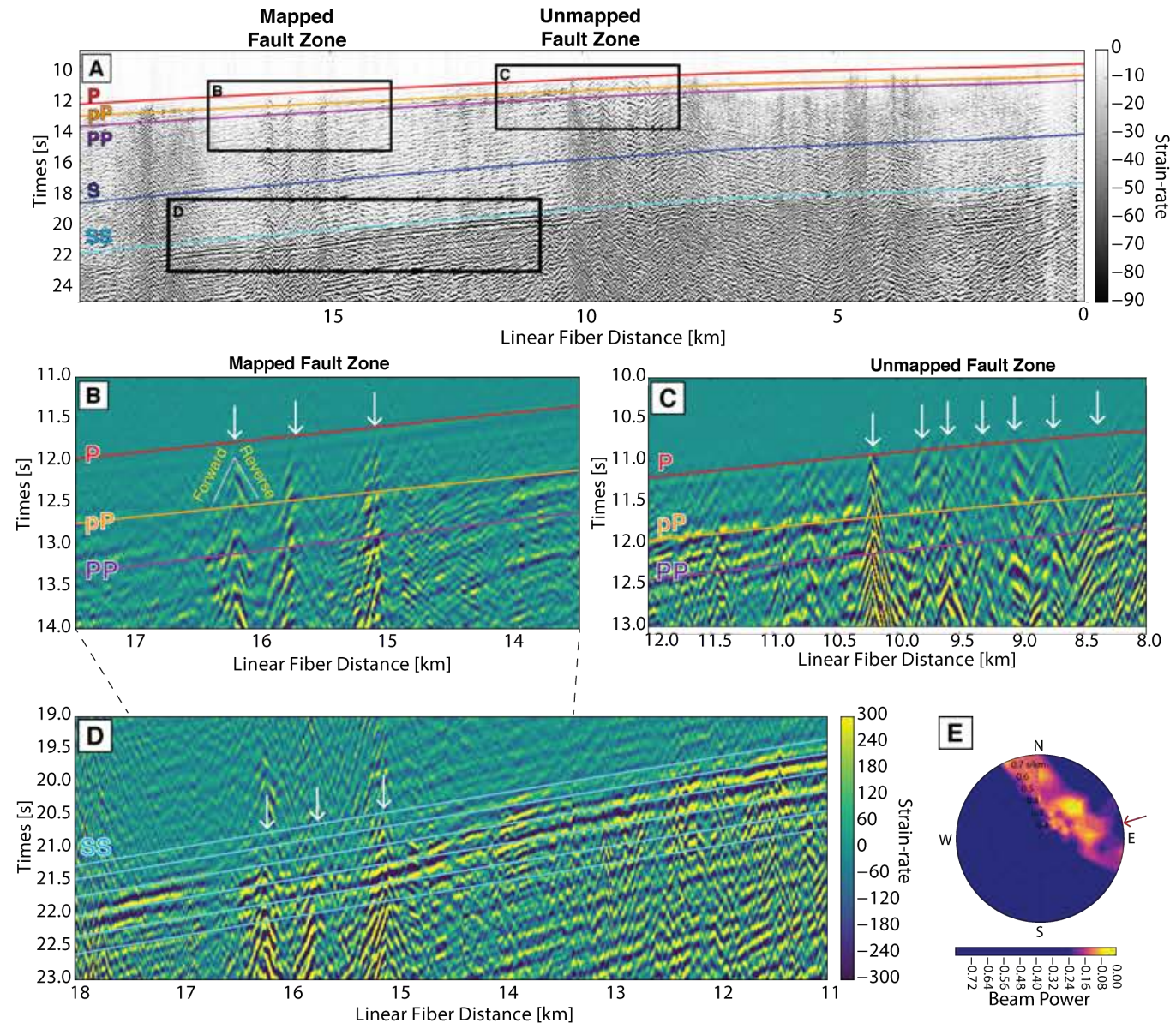

Figure 2: a.) DAS observations of the M3.4 2018-Mar-11 Gilroy earthquake located in Fig. 1 made from 0 - $20 \mathrm{~km}$ along the MARS cable, beginning at Moss Landing. P, pP, PP, S and SS phase arrivals are consistent with predicted arrivals (colored lines) using cable geometry. b.) Inset from (a.) shows discrete secondary scattering in the forward and reverse directions propagating with an apparent velocity of $200-600 \mathrm{~m} / \mathrm{s}$ away from recently-mapped submarine faults (white arrows). c.) Same as (b.) for a previously unmapped fault zone. d.) Inset from (a.) shows SS arrival through the mapped fault zone where it undergoes secondary scattering and $0.25 \mathrm{~s}$ wavefront delay. Lines show predicted constant phase arrivals immediately following the first SS wavefront. e.) Time-domain beamforming solution for a slowness range of $0.05-0.8$ $\mathrm{s} / \mathrm{km}(1.2-20 \mathrm{~km} / \mathrm{s})$ shows how energy arrives from east-northeast-north azimuths. Red arrow shows backazimuth from cable midpoint. 

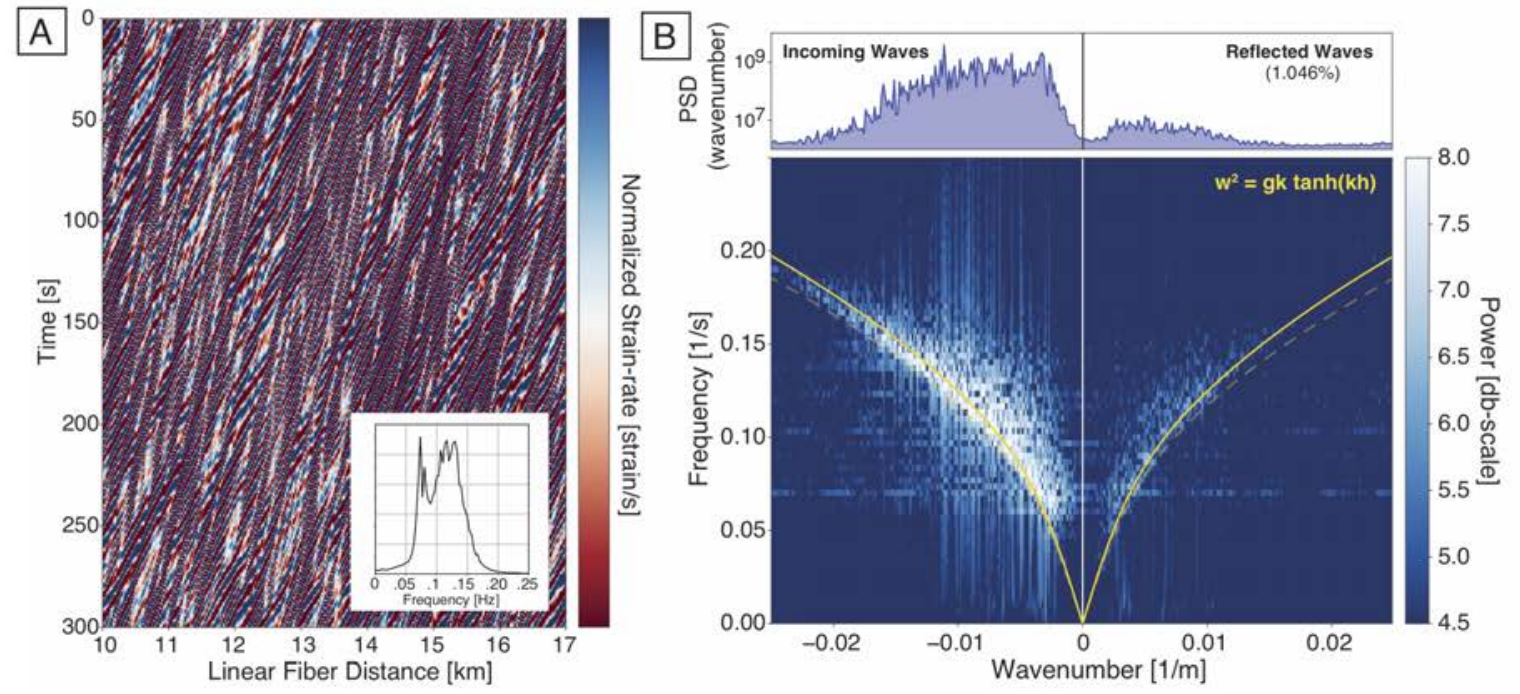

Figure 3: Example ambient noise from a linear section of the MARS cable $(10-17 \mathrm{~km})$ on 2018-Mar-10. a.) Raw seafloor strain-rate data reveals a complicated pattern of wave interaction. Inset shows average spectral content with peak at $\mathrm{f}=0.1 \mathrm{~Hz}$. b.) Frequency-wavenumber projection of (a.) computed by 2-D FFT. Shoaling of ocean wind-waves traveling along a sloping seafloor with a mean water depth of 40-m generates the observed dispersion patterns (yellow curves; solid=wind direction along fiber axis, dashed $=20^{\circ}$ off-axis). According to the LonguetHiggins-Hasselmann hypothesis, oppositely-directed wind-waves associated with primary microseism interact nonlinearly to cause secondary microseism signals with twice the frequency of the primary. The relative magnitude of energy conversion by coast reflection from negative velocity/incoming wind-waves into positive velocity/outgoing waves is observed to be $1 \%$ (upper subplot). 


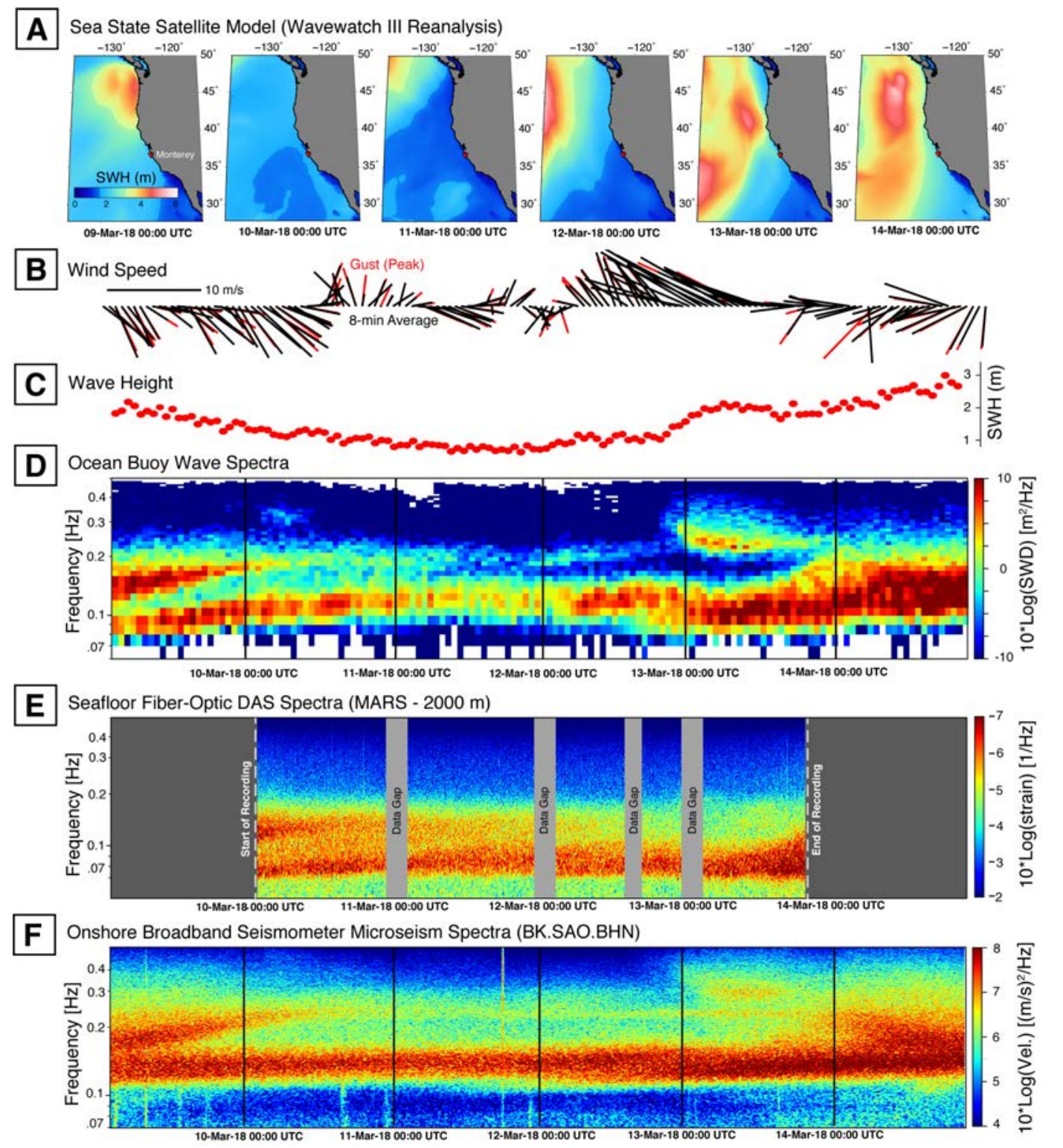

Figure 4: Multi-instrumental time-frequency analysis of sea state evolution. a.) Wavewatch III reanalysis of satellite data shows significant wave height (SWH). b-d.) Monterey Bay NOAA buoy 46042 shows wave speed and direction measurements plotted as 8-min average (black) and peak gust (red), and significant wave height (SWH) and spectral wave density (SWD) from 10-min windows. e.) Seafloor DAS strain from channel 1000 (linear fiber distance=4 km) averaged over a 15-min sliding window, and f.) North component of ground velocity from onshore broadband inertial seismometer BK.SAO.BHN (see Figure 1) averaged over a 15-min sliding window. Red triangle in (a) is buoy 46042. Buoy, DAS and seismometer measurements show time-lapse interactions of primary and secondary ocean microseism between two Pacific storm cycles. 


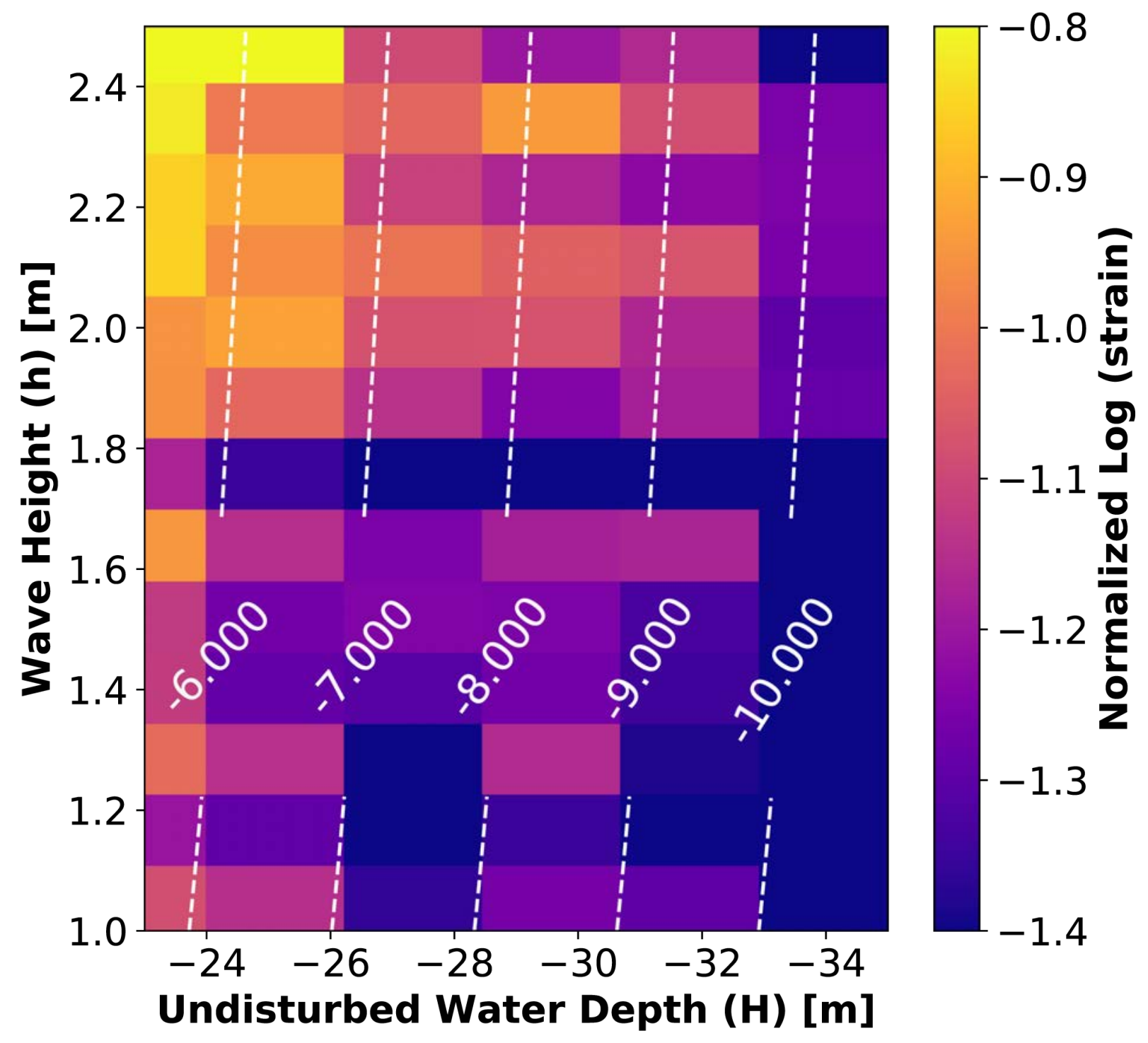

Figure 5: Cumulative DAS strain (image) observed between 1.5 - $20 \mathrm{~km}$ during the 4-day experiment at $\mathrm{f}=0.056 \mathrm{~Hz}$ plotted with seafloor pressure predicted using the buoy-observed wave height (white contours). 


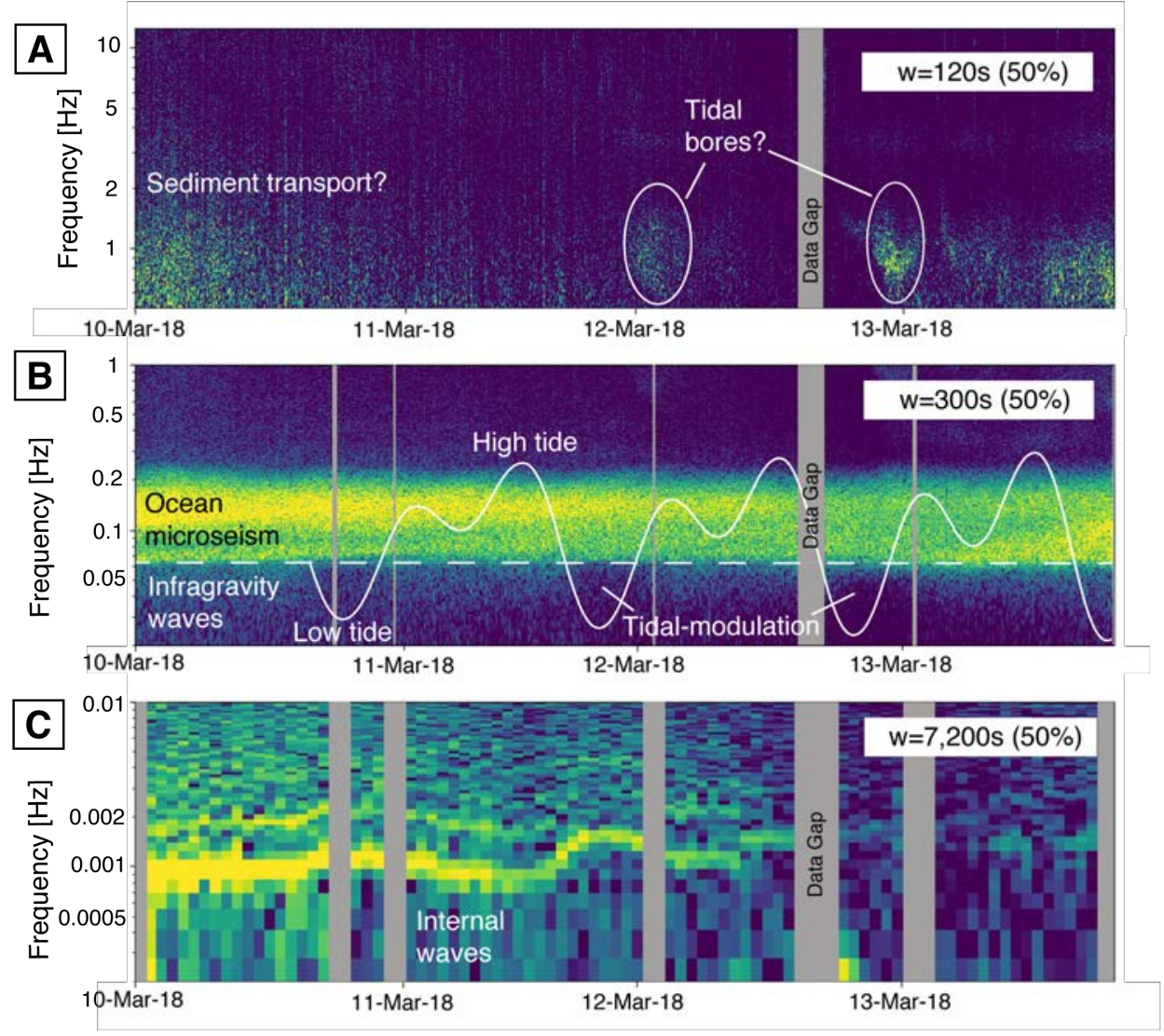

Figure 6: DAS time-frequency analysis at $5.5 \mathrm{~km}$ shows a number of broadband hydrodynamic signals. a.) $0.5-10 \mathrm{~Hz}$ : High-frequency noise consistent with timing of expected storminduced sediment transport (see Figure 4a.) and tidal bore activity. b.) $0.01-0.5 \mathrm{~Hz}$ : Primary and secondary microseism observations (see Figure 3 and 4e.) associated with storm activity, with tidally-modulated infragravity noise below $0.1 \mathrm{~Hz}$; tide gauge from Santa Cruz, CA for reference. c.) $0.0002-0.01 \mathrm{~Hz}$ : Tidally-modulated noise with harmonics, potentially cause by breaking internal waves at the continental shelf or bay seiche oscillations. 


\section{References and Notes}

1. L. A. Levin, et al., Frontiers in Marine Science 6, 241 (2019).

2. C. Wunsch, R. Ferrari, Meteorological Monographs 59, 7 (2018).

3. C. K. Paull, et al., Nature communications 9, 4114 (2018).

4. E. Gracia, J. Danobeitia, J. Vergés, P. Team, et al., Geology 31, 83 (2003).

5. S. Ruiz, R. Madariaga, Tectonophysics 733, 37 (2018).

6. M. Manga, et al., Earth and Planetary Science Letters 489, 49 (2018).

7. N. Ranasinghe, C. Rowe, E. Syracuse, C. Larmat, M. Begnaud, Seismological Research Letters 89, 77 (2018).

8. D. Roemmich, et al., Oceanography 22, 34 (2009).

9. T. Cowles, J. Delaney, J. Orcutt, R. Weller, Marine Technology Society Journal 44, 54 (2010).

10. J. H. Trowbridge, et al. (2019).

11. T. Mittal, B. Delbridge, Earth and Planetary Science Letters 511, 105 (2019).

12. T. C. Dawe, et al., Proceedings of OCEANS 2005 MTS/IEEE (IEEE, 2005), pp. 1-6.

13. B. M. Howe, F. K. Duennebier, R. Lukas, SEAFLOOR OBSERVATORIES (Springer, 2015), pp. $439-463$.

14. C. Barnes, M. Best, F. Johnson, B. Pirenne, Seafloor Observatories (Springer, 2015), pp. 415-438. 
15. D. S. Kelley, J. R. Delaney, S. K. Juniper, Marine Geology 352, 426 (2014).

16. T. Kanazawa, et al., Abstract WE2B-3, Presented at SubOptic 2016 pp. 18-21 (2016).

17. S. G. Wesnousky, Journal of Geophysical Research: Solid Earth 91, 12587 (1986).

18. B. Romanowicz, P. McGill, D. Neuhauser, D. Dolenc, Seismological Research Letters 80, 197 (2009).

19. P. Jousset, et al., Nature communications 9, 2509 (2018).

20. J. B. Ajo-Franklin, et al., Scientific reports 9, 1328 (2019).

21. N. J. Lindsey, et al., Geophysical Research Letters 44, 11 (2017).

22. C. Yu, Z. Zhan, N. J. Lindsey, J. B. Ajo-Franklin, M. Robertson, Geophysical Research Letters 46, 1320 (2019).

23. A. Lellouch, S. Yuan, Z. Spica, B. Biondi, W. Ellsworth, Journal of Geophysical Research: Solid Earth (2019).

24. S. Dou, et al., Scientific reports 7, 11620 (2017).

25. X. Zeng, et al., Bulletin of the Seismological Society of America 107, 603 (2017).

26. E. R. Martin, et al., The Leading Edge 36, 1025 (2017).

27. M. Becker, C. Ciervo, M. Cole, T. Coleman, M. Mondanos, Geophysical Research Letters 44, 7295 (2017).

28. B. Romanowicz, et al., Annals of Geophysics 49 (2006).

29. B. M. Howe, et al., Proc. Scientific Submarine Cable 2006 Conf (2006), pp. 7-10. 
30. L. Kuhnz, J. Barry, K. Buck, C. Lovera, P. Whaling, MARS Biological Survey Report, Monterey Bay National Marine Sanctuary, NOAA (2015).

31. A. J. Rodgers, A. Pitarka, N. A. Petersson, B. Sjögreen, D. B. McCallen, Geophysical Research Letters 45, 739 (2018).

32. S. Y. Johnson, et al., Ocean \& coastal management 140, 88 (2017).

33. K. L. Maier, S. Y. Johnson, P. Hart, Marine Geology 404, 24 (2018).

34. R. A. Haubrich, K. McCamy, Reviews of Geophysics 7, 539 (1969).

35. T. Herbers, R. Guza, Journal of physical oceanography 21, 1740 (1991).

36. P. D. Bromirski, F. K. Duennebier, Journal of Geophysical Research: Solid Earth 107 (2002).

37. J. Zhang, P. Gerstoft, P. D. Bromirski, Geophysical Research Letters 37 (2010).

38. S. C. Webb, Reviews of Geophysics 36, 105 (1998).

39. P. Gerstoft, P. M. Shearer, N. Harmon, J. Zhang, Geophysical Research Letters 35 (2008).

40. W. C. Crawford, S. C. Webb, Bulletin of the Seismological Society of America 90, 952 (2000).

41. M. S. Longuet-Higgins, Philosophical Transactions of the Royal Society of London. Series A, Mathematical and Physical Sciences 243, 1 (1950).

42. K. Hasselmann, Reviews of Geophysics 1, 177 (1963).

43. P. D. Bromirski, Geochemistry, Geophysics, Geosystems 2 (2001). 
44. D. Dolenc, B. Romanowicz, D. Stakes, P. McGill, D. Neuhauser, Geochemistry, Geophysics, Geosystems 6 (2005).

45. H. L. Tolman, D. Chalikov, Journal of Physical Oceanography 26, 2497 (1996).

46. L. Hsu, N. J. Finnegan, E. E. Brodsky, Geophysical Research Letters 38 (2011).

47. V. C. Tsai, B. Minchew, M. P. Lamb, J.-P. Ampuero, Geophysical Research Letters 39 (2012).

48. B. Schmandt, et al., Geology 45, 299 (2017).

49. F. Cazenave, Y. Zhang, E. McPhee-Shaw, J. G. Bellingham, T. P. Stanton, Limnology and Oceanography: Methods 9, 571 (2011).

50. J. A. Colosi, N. Kumar, S. H. Suanda, T. M. Freismuth, J. H. MacMahan, Journal of Physical Oceanography 48, 123 (2018).

51. R. K. Walter, C. B. Woodson, R. S. Arthur, O. B. Fringer, S. G. Monismith, Journal of Geophysical Research: Oceans 117 (2012).

52. G. S. Carter, M. C. Gregg, R.-C. Lien, Continental Shelf Research 25, 1499 (2005).

53. L. C. Breaker, Y.-h. Tseng, X. Wang, Progress in Oceanography 86, 380 (2010).

54. J. Park, W. Sweet, R. Heitsenrether, Ocean Science 11, 439 (2015).

55. C. Garrett, W. Munk, Deep sea research and oceanographic abstracts (Elsevier, 1972), vol. 19 , pp. $823-832$.

56. J. M. Klymak, J. N. Moum, Geophysical Research Letters 30 (2003).

57. W. S. Holbrook, I. Fer, Geophysical Research Letters 32 (2005). 
58. M. H. Alford, et al., Nature 521, 65 (2015).

59. E. Stutzmann, M. Schimmel, G. Patau, A. Maggi, Geochemistry, Geophysics, Geosystems $10(2009)$. 


\title{
Supplementary Materials for: Photonic seismology in Monterey Bay: Dark fiber DAS illuminates offshore faults and coastal ocean dynamics
}

\author{
Nathaniel J. Lindsey, ${ }^{1,2, *}$ T. Craig Dawe, ${ }^{3}$ Jonathan B. Ajo-Franklin ${ }^{2}$, \\ *To whom correspondence should be addressed; E-mail: natelindsey@berkeley.edu.
}

\section{This PDF includes:}

- Materials and Methods

\section{Materials and Methods}

LBNL-MBARI offshore DAS dark fiber experiment

The DAS interrogator was positioned on a passive vibration isolation table in the building where the cable emerges onshore. Continuous DAS recordings were acquired from March 10 - 14 with a few brief interruptions due to power outages associated with cable maintenance. An optical time domain reflectometry measurement of the optical fiber used for DAS showed $0.19 \mathrm{~dB} / \mathrm{km}$ of loss from shore and the MARS node at $51 \mathrm{~km}$, with minimal losses at the instrument connection point. The DAS interrogator used a 10-m gauge length. Laser pulse timing parameters were set to ensure only one outgoing laser pulse was inside the fiber at a time. Channel spacing was set to $2 \mathrm{~m}$, which resulted in 9,984 channels spanning the first $20 \mathrm{~km}$ of cable length. Data were digitized at 500 samples per second to preserve seismological and oceanographic signals below $\sim 200 \mathrm{~Hz}$. A GPS antennae provided accurate timing. DAS data were written continuously via USB 3.0 at $250 \mathrm{MB} / \mathrm{s}$ to an external hard disk. In total, $3.2 \mathrm{~TB}$ of raw optical phase 
rate data (proportional to strain-rate) were recorded during the four-day experiment.

Complimentary datasets were compiled from publically available archives (see Fig. 1 for station locations). Wind speed and direction, significant wave height, and wave density spectra data products were recorded by an accelerometer package onboard NOAA buoy 46042, the only active buoy in Monterey Bay of this expeirment. Buoy 46042 is located $20 \mathrm{~km}$ from shore and $15 \mathrm{~km}$ south of the MARS cable in transitional water depth (http://www.ndbc.noaa.gov/). NOAA tide gauge 9413745 in Santa Cruz, CA provided 6-minute water level records (https:// tidesandcurrents.noaa.gov/; Fig. 6). Continuous onshore seismometer recordings from the Northern California Seismic Network's three-component broadband station SAO (NC.BK.SAO) located $40 \mathrm{~km}$ ESE of Moss Landing were downloaded from the Northern California Earthquake Data Center using the ObsPy FDSN Client module. Because the MARS node was de-energized, seafloor instruments were not available. This included seismometer NC.BK.MOBB and the seafloor hydroacoustic sensors connected to the MARS node.

\section{Earthquake data processing}

Data processing of the raw DAS data records from the 2018-Mar-11 M3.4 Gilroy earthquake involved linear detrending, followed by a standard fk-domain fan filter ( $\mathrm{f}=1-30 \mathrm{~Hz}$; $\mathrm{k}=0 \pm 0.03$ $\mathrm{m}^{-1}$ with edge-tapering) to remove dominant ocean and photonic noise $(1,2)$. Then a moving window-median smoothing operator was applied over 3 gauge lengths $(30 \mathrm{~m})$ to remove photonic fading effects (3).

\section{Earthquake phase prediction}

Synthetic traveltimes for all seismic phases were computed using a radially-symmetric spectral element forward model provided by the InstaSeis package (4). For this numerical calculation we used a modified form of the reference earth model ak135 with a shallow crust model (depth=0- 
$10 \mathrm{~km}$ ) based on (5). No water boundary condition was employed for the offshore portion. We used the USGS catalog moment tensor solution as the input source. Sensing point locations were interpolated from known cable geometry using a 2-m spacing from Moss Landing.

Primary microseism wavefield analysis

Leveraging the array-nature of DAS, a 2-D FFT of an evenly-sampled time-distance array of DAS records decomposes the data into shoreward/incoming and seaward/outgoing components (Fig. 3b). Incoming components have negative velocities $(c=f / k)$ because they propagate from the far end of the cable to shore (channel=0), while the outgoing components register as propagating in the positive (cable) direction.

Multi-instrumental broadband spectrogram analysis

WaveWatch-III is an operational spectral wave model that incorporates NCEP wind and ice field data resolved every 3-hours on an operational basis (https://polar.ncep.noaa.gov/waves/). Storms manifested in the model as regionally-averaged significant water height maxima around 4-6 m (Fig. 4a). Buoy-recorded wave spectra in the microseism band were recorded with an 8-minute resolution (Fig. 4d). DAS strain spectra from a cable position $2 \mathrm{~km}$ were averaged over 2-minute sliding windows (Fig. 4e). The north-component from the high-quality onshore broadband inertial seismometer BK.SAO was also analyzed over 2-min sliding windows (Fig. 4f). Please see Fig. 1 for all sensor locations. 


\section{References and Notes}

1. J. W. Rector III, S. K. Lazaratos, J. M. Harris, M. V. Schaack, Geophysics 59, 27 (1994).

2. Ö. Yilmaz, Seismic data analysis, vol. 1 (Society of exploration geophysicists Tulsa, OK, 2001).

3. J. Zhou, et al., Journal of lightwave technology 31, 2947 (2013).

4. M. v. Driel, L. Krischer, S. C. Stähler, K. Hosseini, T. Nissen-Meyer, Solid Earth pp. 701$717(2015)$.

5. A. J. Rodgers, A. Pitarka, N. A. Petersson, B. Sjögreen, D. B. McCallen, Geophysical Research Letters 45, 739 (2018). 